\title{
CALL FOR PAPERS: GENDER AND THE LAW
}

Law and Human Behavior invites manuscript submissions for a special issue on the interaction between gender and the law. We are interested in research that addresses the diversity of roles men and women play within the legal system. This can include research that examines the differential treatment of men and women within various areas of the law, such as family law (e.g., child custody rights), criminal law (e.g., gender differences in criminal behavior or victimization), and civil law (e.g., sex discrimination). We also welcome research on broader community and systemic issues (e.g., gender bias in the courtroom). Finally, we are interested in research on men and women in the various legal professions, especially those branches of the legal system that traditionally have received less empirical attention (e.g., police, correctional institutions). International and cross-cultural perspectives are encouraged.

Within these broad topic areas, we welcome theoretical and integrative review articles, as well as reports of field and laboratory research. We encourage all authors to discuss the policy implications of their research.

The editors for this issue are Patricia Frazier and Jennifer Hunt of the University of Minnesota. Manuscripts, in triplicate, should be sent to:

Patricia A. Frazier, Ph.D.

Department of Psychology

Elliott Hall

University of Minnesota

Minneapolis, MN 55455

Internet: pfraz@maroon.tc.umn.edu

To be considered for this special issue, manuscripts must be postmarked no later than October 1, 1996. 